Article

\title{
Automatic Detection of Spatiotemporal Urban Expansion Patterns by Fusing OSM and Landsat Data in Kathmandu
}

\author{
Nishanta Khanal ${ }^{1, *(\mathbb{D},}$, Kabir Uddin ${ }^{1} \mathbb{D}$, Mir A. Matin ${ }^{1} \mathbb{D}$ and Karis Tenneson ${ }^{2} \mathbb{D}$ \\ 1 International Centre for Integrated Mountain Development, GPO Box 3226, Kathmandu 44700, Nepal; \\ Kabir.Uddin@icimod.org (K.U.); Mir.Matin@icimod.org (M.A.M.) \\ 2 Spatial Informatics Group, LLC, 2529 Yolanda Ct., Pleasanton, CA 94566, USA; ktenneson@sig-gis.com \\ * Correspondence: nishanta.khanal@icimod.org or khanal.nishant@gmail.com
}

Received: 24 August 2019; Accepted: 23 September 2019; Published: 2 October 2019

\begin{abstract}
During the last few decades, a large number of people have migrated to Kathmandu city from all parts of Nepal, resulting in rapid expansion of the city. The unplanned and accelerated growth is causing many environmental and population management issues. To manage urban growth efficiently, the city authorities need a means to be able to monitor urban expansion regularly. In this study, we introduced a novel approach to automatically detect urban expansion by leveraging state-of-the-art cloud computing technologies using the Google Earth Engine (GEE) platform. We proposed a new index named Normalized Difference and Distance Built-up Index (NDDBI) for identifying built-up areas by combining the LandSat-derived vegetation index with distances from the nearest roads and buildings analysed from OpenStreetMap (OSM). We also focused on logical consistencies of land-cover change to remove unreasonable transitions supported by the repeat photography. Our analysis of the historical urban growth patterns between 2000 and 2018 shows that the settlement areas were increased from $63.68 \mathrm{sq} \mathrm{km}$ in 2000 to $148.53 \mathrm{sq} \mathrm{km}$ in 2018 . The overall accuracy of mapping the newly-built areas of urban expansion was $94.33 \%$. We have demonstrated that the methodology and data generated in the study can be replicated to easily map built-up areas and support quicker and more efficient land management and land-use planning in rapidly growing cities worldwide.
\end{abstract}

Keywords: GEE; remote sensing; Landsat; OSM; built-up mapping; Kathmandu; Nepal

\section{Introduction}

Worldover, cities function to compactly cluster populations and support a high degree of economic activity [1]. Global trends have long been showing that people are migrating from rural areas to cities: in 2018, 4.2 billion people, $55 \%$ of the world's population, lived in cities-and projections estimated the proportion of people in cities will be $68 \%$ by 2050 [2]. Between 2018 and 2050, the urban population of Africa is expected to triple, and the urban populations of Asia are expected to increase $61 \%$ [2]. In addition, over the past 30 years, built area expansion has been outpacing urban population growth, suggesting that cities are becoming less compact rates [3,4]. Most of this growth is expected to occur in small and medium-sized cities, not in mega-cities [5]. The reasons for these migrations are multi-fold and include the lure of reliable food and infrastructure, and a perception of increased economic opportunities, prosperity, and security.

Capital cities are often the greatest recipients of these migrants; this is likely for many reasons, one of which is the impression that due to them being the seat of power, they generally receive substantial investment, are well-planned, and are more accessible [6,7]. Unfortunately in Asia, many capital 
cities have not thoughtfully planned a livable cities, often due to rapid expansion coupled with poor management capacities, and compounded by other long-standing factors (such as the original city being built on unsuitable land) [8,9]. However, even when people are aware of the less-than-positive state of various cities and their facilities, they still migrate to them because they may have no other options $[10,11]$. due to pervasive and growing poverty, or increasingly frequent natural disasters that cause migrations to food secure urban centers [12]. Growth can, unsurprisingly, cause negative environmental (and socio-economic) impacts on the existing city environment and surroundings if there are no plans to accommodate the growth [13]. For one, the continuous expansion of impervious surfaces results in a host of water issues, from flooding, to inadequate aquifer refill, to soil erosion [14]. To preserve ecosystem services, like those that well-managed water can provide, city planners and policymakers must know the relationship between built-up area expansion and ecosystem services [15].

Nepal is one of the ten least-urbanized countries in the world, yet its' capital city, Kathmandu, situated in the Kathmandu valley, is one of the top ten fastest-urbanizing cities in the world [16]. According to the National Population and Housing Census, 2011, one million people reside in the Kathmandu valley. Demographic projections forecast that the population could be doubled by 2030 [17]. Migration into Kathmandu is driven by the desires of rural populations to have access to better education, health care, and security, and amenities, such as entertainment, better food, and shopping. In recent years large areas of cropland on the outskirts of Kathmandu have been converted into built settlements, often in a haphazard manner. Homes and other built infrastructure in the valley places development pressure on floodplains and agricultural fields, resulting in flood-prone human settlements, less land to grow crops, and a loss of other ecosystem services [18-20].

The vast transformation of cropland and flood plains to urban settlements have left a trail of diverse problems for Kathmandu city. Timely and accurate information on the annual trends of settlement patterns can play a very critical role in resolving those environmental issues [20]. Further, it is important to inform better land-use plans and placement of social services to meet the needs of growing neighborhoods. It can help municipal authorities monitor urban growth patterns, better allocate land for residential or commercial uses, and reduce the impacts of potential environmental disasters. Some policies are now being formulated and implemented to achieve balanced distributions of populations in different towns and cities across region; these policies mainly focus on financing for urban infrastructure and services. However, use of geospatial information on a regular basis for implementation planning processes is largely unavailable or difficult to manipulate. Therefore, there is a need for a reliable and up-to-date database on changes in urbanization patterns.

Historically, urban geographers have preferred to use remotely sensed information, such as aerial photographs, to identify settlement areas. This can be challenging considering the operational costs and human resource talent needed for regular urban mapping. For the last twenty years, urban spatial analysis products derived from digital image processing techniques and satellite data have improved urban management [21], particularly in understanding the spatial and temporal complexity of rapid expansion in places like Kathmandu. In addition to commercial high-resolution images, many urban studies have used medium-resolution data collected from Landsat Thematic Mapper (TM), Enhanced Thematic Mapper (ETM), and Landsat 8 to separate built-up areas from other land covers, which is a technologically sound approach and is cost effective [22].

For accurate mapping of built-up areas, the Normalized Difference Built-up Index (NDBI) is often employed. This method has some limited accuracy whenmapping urban built-up areas [23]. In many cases, Landsat images alone are insufficient for accurate mapping of built-up areas because the spectral response of impervious surfaces such as roads are similar to other land cover types, such as barren areas, especially in cities located in arid or semiarid environments. Another issues is that the spectral signature of narrow urban features, such as road corridors, can be difficult to differentiate at the 30-m resolution provided by Landsat. Therefore, fusion with other thematic vector layers can improve built-up area mapping methods that rely on Landsat alone [20,24,25]. 
Recently, OpenStreetMap (OSM), an emerging crowd-sourced data set [26], has been drawing attention as a means to extract urban information [27,28]. OSM layers are updated frequently by volunteers through a collaborative, free, open-access approach. These data have been widely used over the last decade as a supplementary source of information for land-use mapping, and have been especially valuable in classifying artificial surfaces [29]. The most common use is combining OSM and satellite images to extract information related to the urban environment [30-33]. For example, useful and good-quality land use/land cover (LULC) information was extracted using OSM and GlobeLand30 in Kathmandu and Dar es Salaam with good results Fonte et al. [34]. In most cases, the focuses on obtaining the most current OSM data; much more could be done to obtain historical or time-series land cover data using OSM. While there have been some studies on using OSM for time-series data $[31,35,36]$, they either rely time information stamped on the data, or try to use OSM alone to classify images.

Although, several desktop-based Geographic Information System (GIS) and remote sensing tools have been used for urban spatial analysisstudies [37-39], these tools require different functionalities and computational power for satellite image processing vs. urban mapping. Typically, desktop-based tools are unable to handle large multi-temporal data sets and produce quality products within the short periods of time needed in a rapid urban development and planning environment $[40,41]$. Therefore, in order to classify a large number of Landsat scenes without downloading, a robust online tool that has a high performance computation capacity is required. Google Earth Engine (GEE) is a commonly used cloud-based analysis platform because it provides global, publicly available, multi-petabyte geospatial satellite imagery and data sets with planetary-scales at no cost [42]. In comparison to the time limit of desktop image processing, GEE is the most advanced cloud-based image processing platform capable of processing extremely large areas and performing land cover mapping promptly. Google has collected large amounts of publicly available remote sensing satellite data from around the world and provided image analysis functionality for various thematic areas and spatial scales.

Recent efforts of developing Nepal land-cover maps using various methods show that mapping built-up areas has been tricky because of spectral mixing with riverbeds and barren areas. Therefore, the primary objective of this study was to develop a computationally and cost-efficient method to accurately provide annual built-up area information to assist in urban land-use planning. In order to achieve this, we propose a new index that combines Landsat data for its massive earth observation data archive and OSM for its precise, current, and crowd-sourced vector data. The fusion of time-series Landsat satellite images and crowd-sourced OSM data for settlement area mapping led to higher classification accuracy not only for mapping current land cover but also for studying historical patterns. This helps us overcome the limitations of spectral mixing in Landsat images as well as the absence or lack of timed information in OSM. Ergo, our research has produced built-up area layers that will be valuable for generating regional land cover maps for the Hindu Kush Himalayan (HKH) region. Such a method can be used online, and does not require costly computing technology, and thus can be a useful tool for development practitioners, land planners and policymakers world over.

\section{Study Area and Data Used}

The bowl-shaped Kathmandu valley was chosen for our study because the city has been facing rapid urbanization issues over the past decades. Kathmandu valley is located in Province No. 3 of Nepal, situated between $27^{\circ} 36^{\prime}$ and $27^{\circ} 48^{\prime} \mathrm{N}$ and $85^{\circ} 12^{\prime}$ and $85^{\circ} 31^{\prime} \mathrm{E}$ (Figure 1). It includes three districts, Kathmandu, Lalitpur, and Bhaktapur, totalling an area of around $899 \mathrm{sq} \mathrm{km}$. Kathmandu valley is surrounded by four major green mountain ranges, Chandragiri, Nagarjun, Phulchowki, and Shivapuri, which occasionally experience snowfall. The rest of Kathmandu valley is characterized by gently sloping areas and fertile agricultural land. The main river flowing through the city, the Bagmati River, has experienced drying during recent decades. The elevation varies from 421 to $2922 \mathrm{~m}$, with a mean slope of $16 \%$ and a range from $0 \%$ to $58 \%$ [43]. 


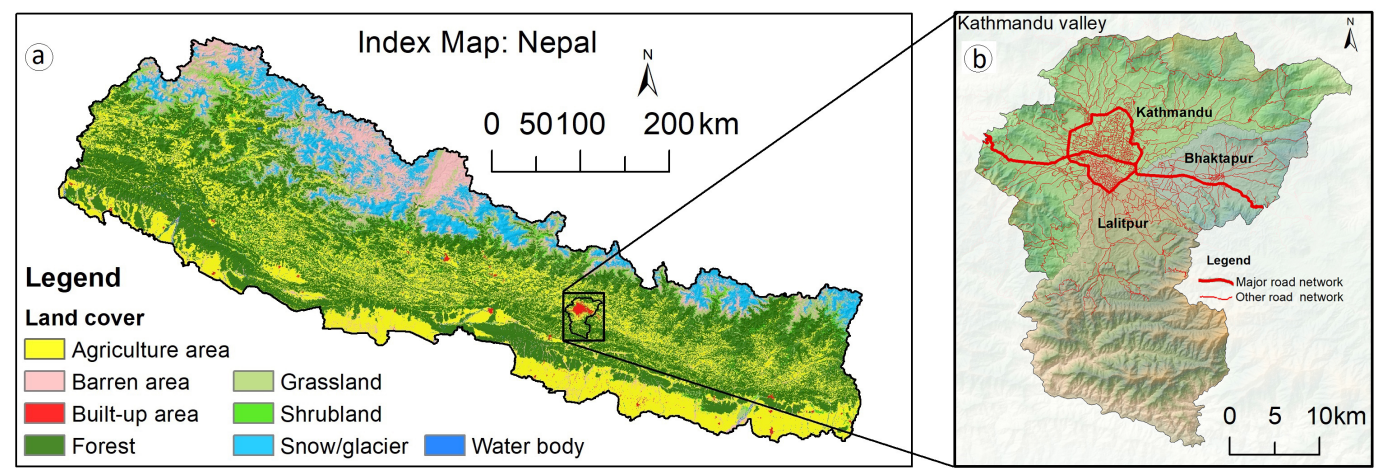

Figure 1. Map of the study area: (a) The 2010 national land-cover map of Nepal, with the inset depicting the location of Kathmandu metropolitan region. (b) Kathmandu Valley is located in the central part of Nepal. It includes three districts: Kathmandu, Bhaktapur, and Lalitpur.

Kathmandu valley is the most populated and developed urban agglomeration in Nepal, with 2.5 million people and 613,000 households in 2011 [44]. By 2030, the population in the Kathmandu district alone is expected to nearly double [16]. The city is the major economic hub of Nepal. It serves as the country's tourism center, home to seven world heritage sites andis a gateway to the Nepalese Himalayas. Growth in the Kathmandu valley has outpaced infrastructure investments and land-use regulation enforcement; in particular, enforcement of land-use policies for detailed area planning has been inadequate and there are gaps in supplies for basic services. Despite these issues, the influx of population remains rapid because Kathmandu is has topography, accessibility, and commercial activities that many desire, and provides a haven for rural people pushed out of their homes by disasters [20,45]. Such massive migration from rural areas is also common in other cities of Nepal, particularly in the center of the country. [46-50].

We merged information from Landsat images with the building and road information available in OSM data sets to improve the quality of built-up area mapping. All available Landsat Thematic Mapper (TM), Enhanced Thematic Mapper Plus (ETM+), and Data Continuity Mission (LDCM) satellite images were used to map the evolution of urban lands. The Landsat Surface Reflectance Tier-1 processed data for each mission is available in Google Earth Engine at the native resolution of $30 \mathrm{~m}$. This suite of Landsat satellite images offer a continuous, long-term data archive, with revisit frequency at each unique row and path combination every 16 days [51]. Kathmandu valley is located within Landsat row 41, path 141. All the Landsat 5, 7, and 8 surface reflectance images were used in this study, except Landsat 7 scenes acquired after 2003 because of the SLC failure.

Earth observation optical satellite images are affected by distortion from atmospheric and topographic affects. These need to be removed in order to represent the land cover at the Earth's surface so it is possible to detect spatiotemporal urban expansion trends in Kathmandu valley. The USGS Landsat 8 surface reflectance product has already been orthorectified, has been topographically and atmospherically corrected using the Landsat Surface Reflectance Code (LaSRC) [52-54], and also contains the data produced by hlCFMASK [55]. We applied additional preprocessing steps to the data set. These include the surface bidirectional reflectance distribution function to reduce noise at the edges of scenes between adjacent images collected on the north to south and the south to north images orbits [8,54]. Clouds were masked using the pixel-qa band and a cloudScore algorithm, described in Reference [56]. We also used the Temporal Dark Outlier Mask (TDOM) algorithm to remove cloud shadows $[57,58]$. This approach identifies pixels that are dark in the infrared bands but are found to not always be dark in past and/or future observations.

OpenStreetMap (OSM) data is a crowd-sourced data set, where the layers are updated on a regular basis by volunteers [26]. We downloaded available OSM data covering Kathmandu valley on November 10, 2018, using the overpass application programming interface (API) in overpass turbo web application (https: / / overpass-turbo.eu/). Next, we processed the OSM layers. The buildings and 
roads were obtained by making feature queries on the overpass API as follows (Table 1). The extracted features were saved as a raster with a spatial resolution of 30 meters.

Table 1. Overpass application programming interface (API) query used to extract information about roads and buildings from the OpenStreetMap (OSM) database.

\begin{tabular}{cc}
\hline For Buildings & For Roads \\
\hline way & way \\
[building = yes] & {$[$ highway] } \\
$(\{\{$ bbox $\}\}) ;$ & $(\{$ bbox $\}\}) ;$ \\
$\left(. \_;>;\right) ;$ & $\left(. \_;>;\right) ;$ \\
out; & out; \\
\hline
\end{tabular}

The query checks for ways which are used for both lines and polygons in OSM in both cases. In case of buildings, the [building = yes] checks for features with attribute building set as yes. In the case of roads, it is just looking for the presence of the tag highway. Other parameters are intended to fetch all features associated with that in the bounding box bbox.

\section{Methodology}

The study was carried out by fusing layers generated from OSM and earth observation-derived data from Landsat 5, 7, and 8. Figure 2 presents the overall methodology of this study. First we preprocessed Landsat images to remove distortion, such as error from terrain, clouds, and cloud shadows. Buildings and road features were next extracted from OSM data sets and we created annual NDVI statistics. These were integrated with information about the distance to the nearest building or road feature from the OSM data. The integrated metric, henceforth referred to as Normalized Difference and Distance Built-up Index (NDDBI), was then inspected on reference points. A threshold is decided upon based on this to classify image for each year. The results are then checked and corrected for logical urban land-cover transitions. Accuracy assessment was done on the final results through confusion matrix and visual assessment. This integration of NDDBI for automatic urban mapping from 2000 to 2018 required analysing a large number of Landsat scenes and OSM data sets for which GEE was selected because of its high computational capabilities and cloud-based nature [42].

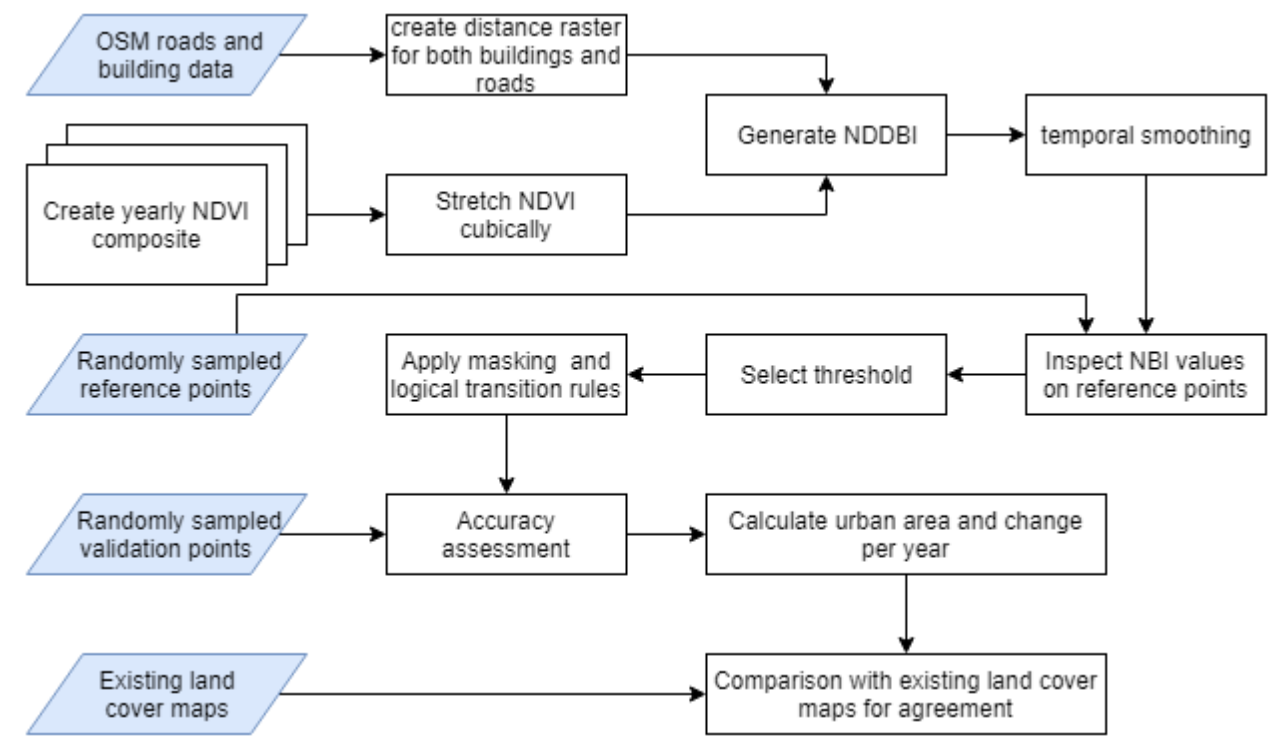

Figure 2. Overall methodology of the study. 


\subsection{Calculating Annual Normalized Built-Up Index}

We propose the use of the metric NDDBI generated using Normalized difference vegetation index (NDVI) and the distance to roads and buildings represented in OpenStreetMap (OSM). We use NDDBI to map the evolution of built-up areas between 2000 and 2018. NDDBI is the result of multiplying the (rescaled) annual 80th percentile NDVI values by the sum of the distance to the nearest road and building features from OSM. We describe the processing steps in the section below.

First, we calculated the NDVI time series from the preprocessed Landsat data stack. Annual image composites were created using the corrected Landsat 5, 7, and 8 image scenes; annual statistics include median values and 20th and 80th percentiles. These statistics on each Landsat band were saved to create an annual multi-band image, stored in an image collection as a GEE asset. NDVI was calculated on each image, and the annual 80th percentile value was recorded for each year (Equations (1) and (2)). NDVI has a strong positive relation with the vegetated and negative relation with build-up areas. NDVI indices range from -1 to 1 : densely developed infrastructure areas will have values approaching zero, while healthy vegetated canopy areas values can range from 0.3 to 0.8 [59]. NDVI works well to track changes in vegetation signals associated with converting forest or agriculture land into urban/built-up. In such scenarios, once the land cover has changed to urban, the maximum NDVI within a year drops significantly. The 80th percentile of NDVI over the year was used instead of the maximum value in order to avoid noise and inconsistencies. Finally, we modified the stretch of the NDVI values: converting them to a positive scale and exaggerating the difference between the minimum and maximum NDVI values. This was accomplished by adding 1 to the NDVI values and then by applying a cubic stretch (Equation (3)).

$$
\begin{gathered}
N D V I_{\text {scene }}=(N I R-R E D) /(N I R+R E D) \\
N D V I_{\text {composite, } y}=80 \text { th percentile of NDVI scenes within year y } \\
N D V I_{y}=\left(N D V I_{\text {composite } y}+1\right)^{3}
\end{gathered}
$$

Next, we calculated the distance from OSM building and road features in GEE. The OSM buildings and roads rasters were used to create distance layers in meters with a 30-m spatial resolution (Equations (4) and (5)).

$$
\begin{gathered}
\text { DIST }_{\text {road }}=(\text { Normalized distance from Road }+1) * 10 \\
\text { DIST }_{\text {building }}=(\text { Normalized distance from Road }+1) * 10
\end{gathered}
$$

We multiplied the distance rasters with the annual NDVI layers. We first removed zeroes in the road and building distance raster by adding 1 to all pixel values. It is important to remove zero values regardless of how high the NDVI was in order to properly classify vegetation in historic images prior to urban development activities. The distance values were also scaled by a factor of 10 to improve readability as well as to work with integer values while preserving subtle differences in values across the landscape. Finally, NDDBI was calculated by multiplying the NDVI value by the sum of the distance to the nearest road and building; this value was then rescaled by multiplying by 100 and by converting to an integer (Equation (6)).

$$
N D D B I=N D V I_{y} *\left(D I S T_{\text {road }}+D I S T_{\text {building }}\right) * 100
$$

The NDDBI value decreases as land cover gets converted to urban surfaces. However, the signal is also prone to slight drops associated with other activities on the land, such as years with low rainfall. Therefore, we temporally smooth the time-series data before running the classification so that these points of time with subtle changes in the NDDBI signal are not erroneously classified as urban. The smoothing reduces the amount of illogical transitions to urban in one year and back to vegetative 
cover in subsequent years. The time series was temporally smoothed using the Whittaker smoothing algorithm, with a $\lambda$ value of 5 and $d$ (order of differences) as 3 [60]. This provides a more consistent temporal signal to use to assess changes in land cover, specifically urbanization.

$$
\left(I+\lambda D_{d}^{\prime} D_{d}\right) z=y
$$

where

$\mathrm{I}=$ Identity matrix

$\lambda=$ Smoothing degree; the larger $\lambda$ is, the smoother $\mathrm{z}$ will be

$\mathrm{D}=$ Differential matrix with $\mathrm{m}-2$ rows and $\mathrm{m}$ columns, with $\mathrm{d}$ as the order of differences.

\subsection{Time-Series Classification of Urban Lands}

After applying the temporal smoothing to the NDDBI time series, we tested thresholds to distinguish built-up areas from the other land covers. We used a set of reference points to identify an optimum threshold. The reference points were located randomly in Kathmandu Valley and labeled using high-resolution images in Google Earth.

Using thresholds alone to separate built-up areas produced many false positives, especially in classes with low spectral separability such as barren areas and temporary fallow lands close to settlements. Therefore, in order to reduce false positives, we used 2018 as the baseline urban data set and applied the classification backwards from 2018. To create the 2018 basemap, we first masked the 2018 thresholded NDDBI urban layer using building and road features from the OSM data. This removed pixels classified as urban based on the spectral information, but that did not overlap building or road features in the OSM data set. Next, using this 2018 layer as our baseline, we applied the same approach for the 2017 classification that was completed using the NDDBI raster alone. This approach was used to maintain a progression of logical urban development, ensuring that built-up areas are not changing to other land-cover classes after development. The same procedure was applied for all images from 2000 to the 2018 baseline image. The workflow is diagrammed in Figure 3.

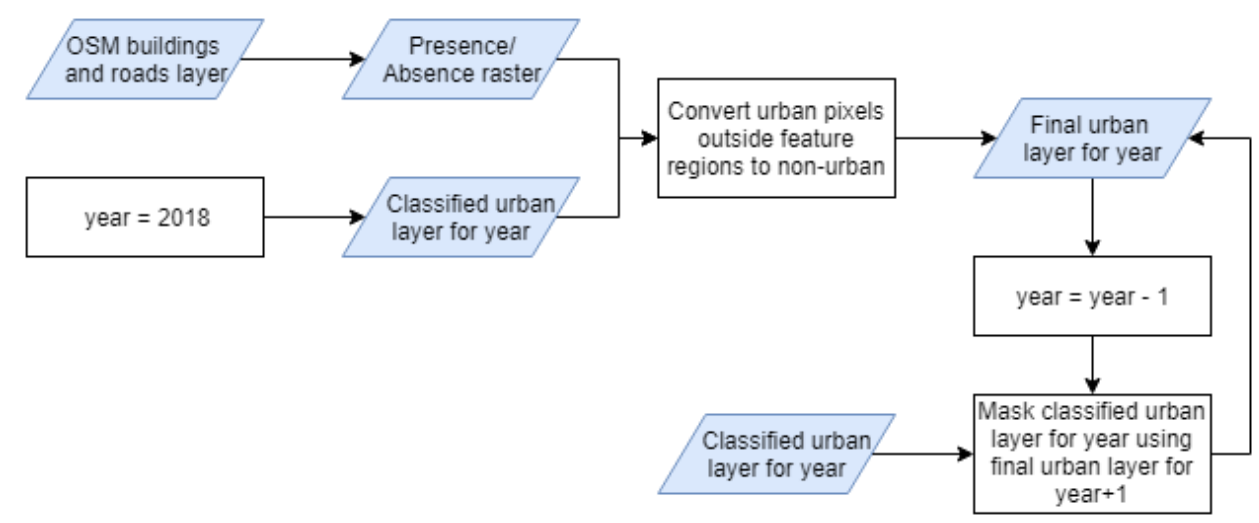

Figure 3. Backpropagation of updating built-up areas to preserve logical consistency of land-cover change.

\subsection{Accuracy Assessment}

To assess the performance of the classification, reference points were collected using random sampling techniques for each year. The reference points were labelled using visual interpretation on images of their respective years and had a total of 935 points. Each point was labeled with the year it was collected and whether it was urban. The points were then sampled on the resulting land-cover data, once again, for their respective years. Using this sample, we prepared a confusion matrix. After running the error matrix, we used this information to estimate the unbiased area of built-up lands for each year [61,62]. 
Additionally, we visually compared the maps to historic photographs. In this step, the vantage point location of each photograph was identified based on historic photo availability, accessibility, and changes on the ground. These sites were revisited, and recent pictures were taken in the same direction. We tallied the built-up area changes on the map with changes on historic and recent photos of the same location. On each photo pair, we inserted a grid to easily inspect built-up area proportions $[63,64]$.

\section{Results}

The results of inspecting the NDVI layer in 2000 show that Kathmandu valley had approximately a 1011-sq-km area with p80 NDVI above 0.30. Due to urbanization, this was decreased to $947 \mathrm{sq} \mathrm{km}$ in 2018, along with a significant decrease in vegetation, and was randomly inspected by the NDVI trend in the twelve locations (as shown in Figure A1 in Appendix A) where the land cover had changed into the settlement presented in Figure 4. The plotted graph shows that there was generally a significant drop in NDVI values associated with the conversion from other land cover types into built-up areas. Upon inspecting the yearly values of NDDBI on the same points, the drastic decline can be observed in Figure 5, which also shows the time series of NDDBI after it was temporally smoothened. The trend is most apparent in this smoothened NDDBI plot.

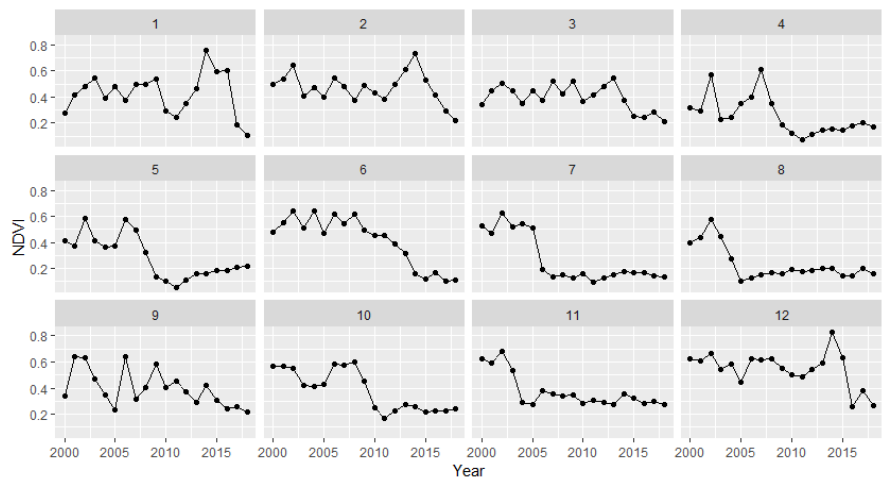

Figure 4. Time series of yearly 80th percentile normalized difference vegetation index (NDVI) in 12 points in the study region that show transition to urban areas. The final dip in NDVI value, which does not rise again, can be observed and inferred to as the point in which the land cover transitioned in all the points.

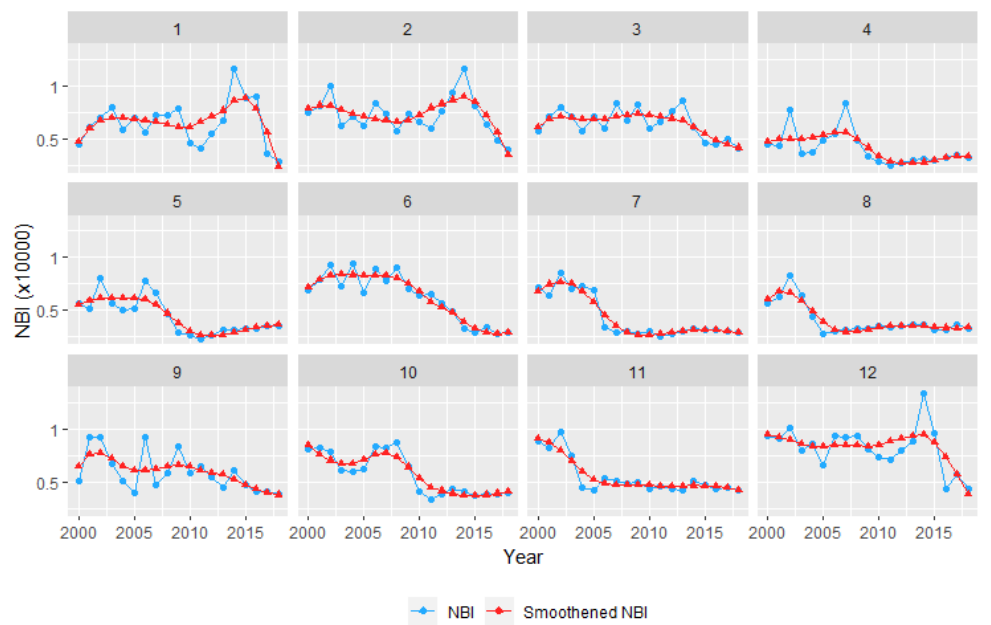

Figure 5. Time series of Normalized Difference and Distance Built-up Index (NDDBI) and Smoothened NDDBI in the same 12 points obtained after combining NDVI and distance layers from OSM data: The NDDBI data follows a similar pattern to that of the NDVI plot.The smoothened NDDBI makes the point of change in land-ctover type more identifiable. 
The NDDBI layers were sampled to identify a suitable threshold to delineate urban lands from other lands (Figure 6). Based on the graph, as well as trial and error to maximize classification accuracy, an NDDBI value of 6300 was selected as the threshold. This threshold was applied across the time series to estimate urban areas for each year.

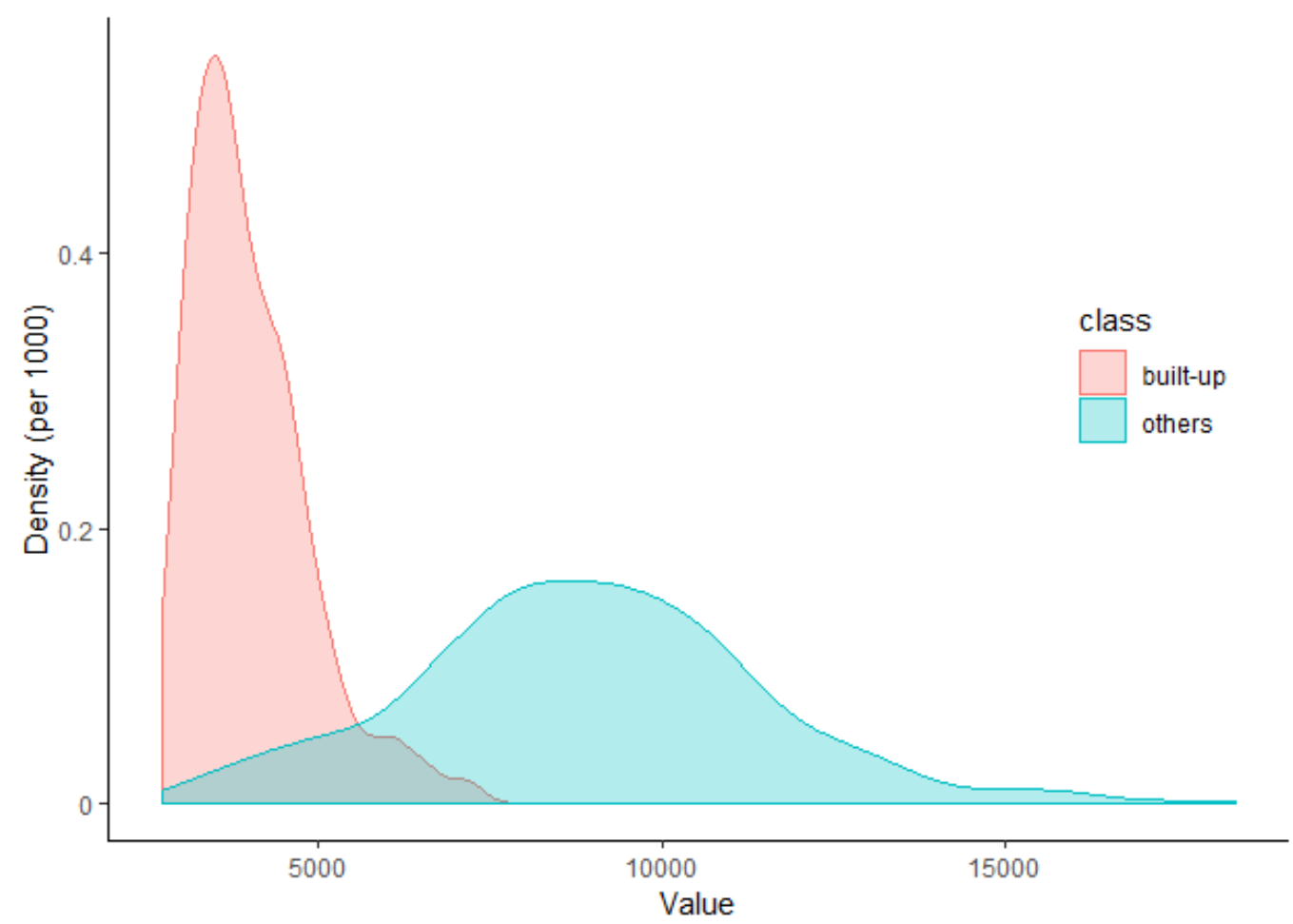

Figure 6. Distribution of smoothened NDDBI values in reference points of the "built-up" class and "others" class collected across the years from 2000 to 2018.

A time series of binary urban cover maps was prepared for the years 2000 to 2018 , and can be seen in Figure 7. The accuracy of overall classification was done using validation points generated from random sampling was $94.33 \%$. These maps show a trend of a growing urban area within the study region. From the maps, it is clear that not only is the urban area spreading outwards but also the area is getting denser as well with other lands within the urban region being converted. The results show that in 2000, urban areas covered $63.68 \mathrm{sq} \mathrm{km}$, while in 2018, that increased to $148.53 \mathrm{sq} \mathrm{km}$. This means that, in 18 years, the urban area in Kathmandu valley has more than doubled $(233.26 \%)$. An alarming statistic is that the increase in urban area from 2015 to 2018 (43.86 sq km) has already exceeded the increase from 2000 to 2014 (40.99 sq km) and it does not look to be slowing down.

From trend maps for area increases (Figure 8), it is apparent that 2003, 2004, 2017, and 2018 are the years that have had the highest increases in urban area with $9.04 \%, 7.67 \%, 11.53 \%$, and $16.65 \%$, respectively. The high rates in 2003 and 2004 line up with the influx of people caused by the civil war, which ended in 2006, when high growth rates peaked. This coincides with the low change rate from 2006 to 2015. The high rate of increase in built-up areas in 2017 and 2018 is likely due to the reinvigorated construction efforts on the aftermath of the 2015 Gorkha earthquake, which also saw the willingness of people to move from crowded settlements to suburbs and outskirts. While the rate of increase in 2003 and 2004 is still low compared to 2017 and 2018, we believe this is because settlements became denser during that time than spreading out. This can be seen when comparing the 2002 map with the 2005 map, where more pixels within the core areas have converted than on the outer regions. 

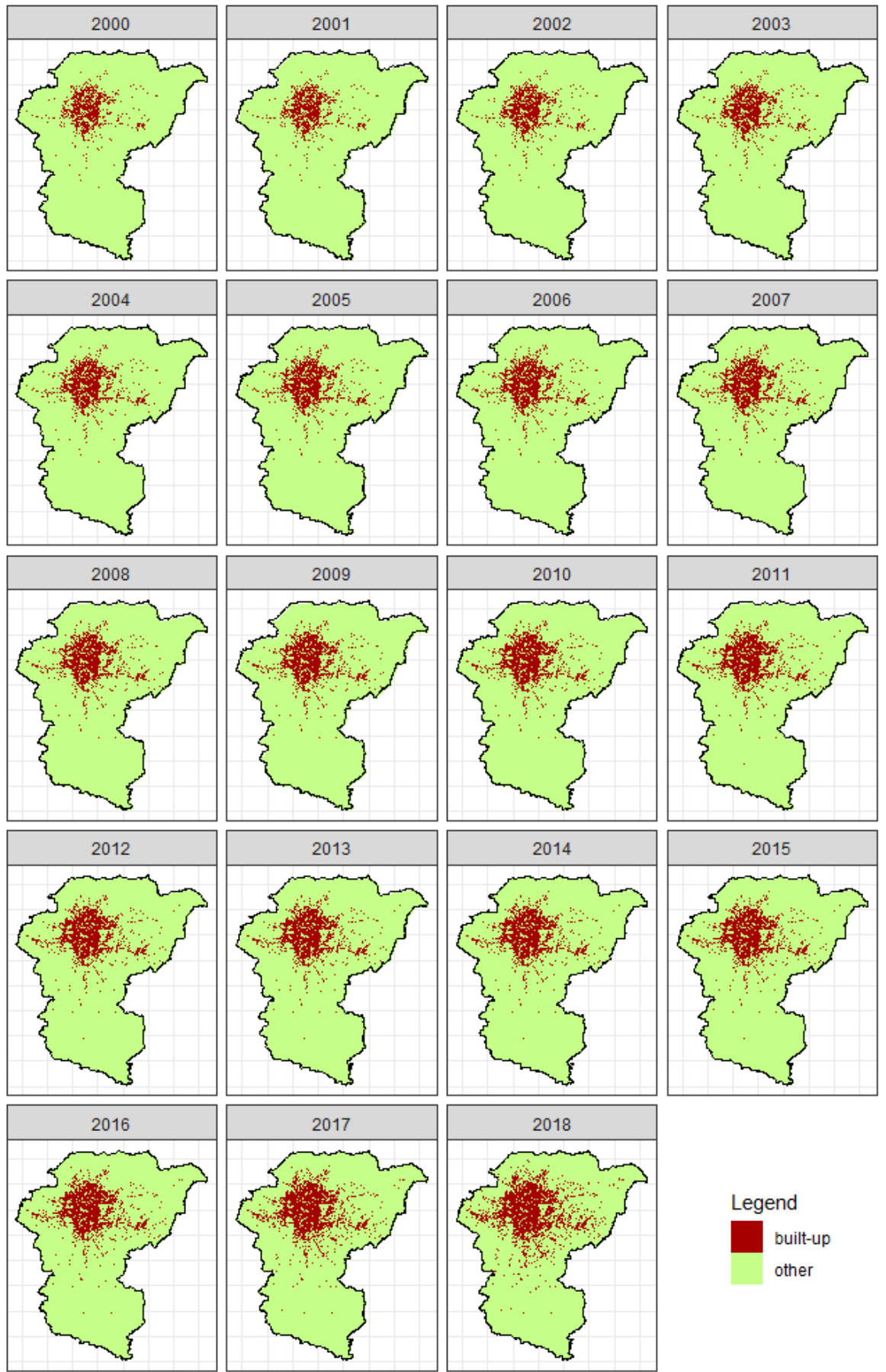

Figure 7. Built-up time-series maps of the study region starting from 2000 to 2018 showing built-up areas (red) and other areas (green): The urban sprawl patterns can be seen from the increase in built-up area coverage. 


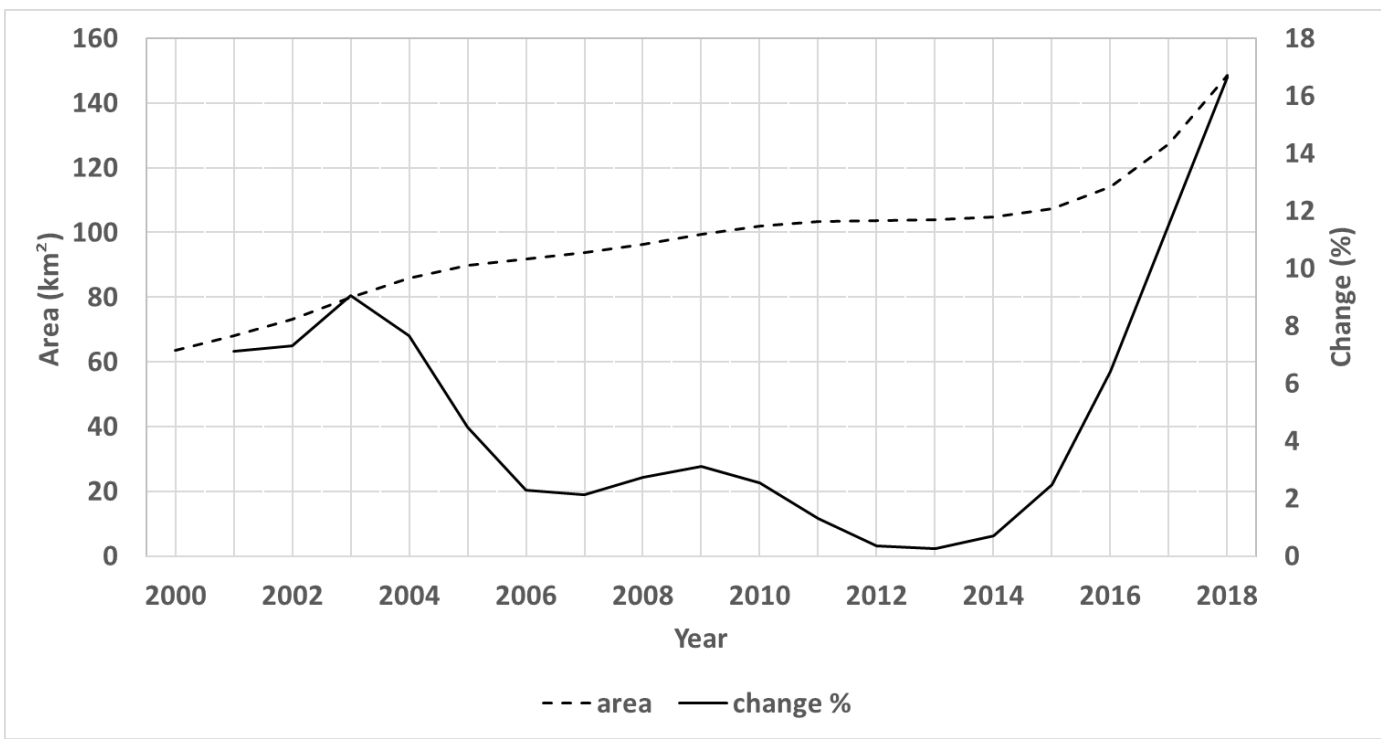

Figure 8. Settlement area and increased percentage in the study region from 2000 to 2018.

Among the three districts within Kathmandu Valley, in 2018, the Kathmandu district had the most urban areas among the three, with $94.56 \mathrm{sq} \mathrm{km}$, followed by Lalitpur with $33.42 \mathrm{sq} \mathrm{km}$, and finally by Bhaktapur with $20.54 \mathrm{sq} \mathrm{km}$. The built-up area in kathmandu has more than doubled between $2000(46.69 \mathrm{sq} \mathrm{km})$ and $2018(95.56 \mathrm{sq} \mathrm{km})$. In the case of Lalitpur, there is a similar trend with area increasing to $268.21 \%$ of its initial $12.46 \mathrm{sq} \mathrm{km}$ in 2000 . As for Bhaktapur, the urban area more than quadrupled (454.32\%) from $4.52 \mathrm{sq} \mathrm{km}$ in 2000. From these results and the population-change percentage obtained from Nepal census 2001 and 2011 for the Kathmandu (61.2\%), Bhaktapur (35.1\%), and Lalitpur (38.6\%) districts, it can be inferred that recent built-up expansions are concentrated more on Bhaktapur and Lalitpur rather than Kathmandu [44,65].

Upon inspecting the spatiotemporal patterns of built-up area expansion of the study region, it becomes clear that the built-up area is spreading outwards from the core Kathmandu area in all directions. The northern, southern, and southwestern parts are especially rapidly being converted. This pattern has been consistent since 2000. However, in recent years, much of the non-built-up pockets within the core region have started converting as well, which means built-up areas are not only spreading outwards but also becoming dense in the core areas. Eastern and southeastern outskirts show large patches of area that have recently been converted to built-up areas. These patterns can be observed in Figure A2 in the Appendix B section.

The classification was also compared with existing land-cover maps of the years 2000 and 2010 [66], which showed that the agreement for the urban area was lower than expected. The Kathmandu district had a $72.35 \%$ agreement in 2010 and a $63.44 \%$ agreement in 2000. Lalitpur had $66.85 \%$ and $52.80 \%$ agreements in 2010 and 2000, respectively. Bhaktapur had the lowest agreements with $24.9 \%$ in 2010 and $13.26 \%$ in 2000 . The existing land cover includes airports as well some private/public recreational grounds in the built-up land class, which was the expected source of disagreement. Upon inspecting the existing land cover and the results with a satellite image, we found that the previous land-cover map was overestimating urban areas because it was classifying croplands and bare fields as built-up areas. Two examples can be seen in Figure 9. In this study, one of the visual witnesses of settlement area expansion was provided by historical geo-tagged landscape photographs. Interpretation of repeat photos for the same location and angle for the particular sites unequivocally show that, between 2008 to 2019, a larger amount of cropland of Kathmandu was converted to built-up areas (Figure 10). 

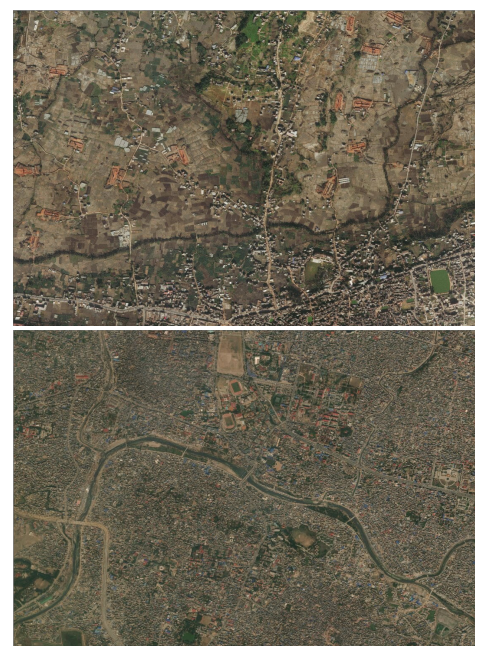

(a)

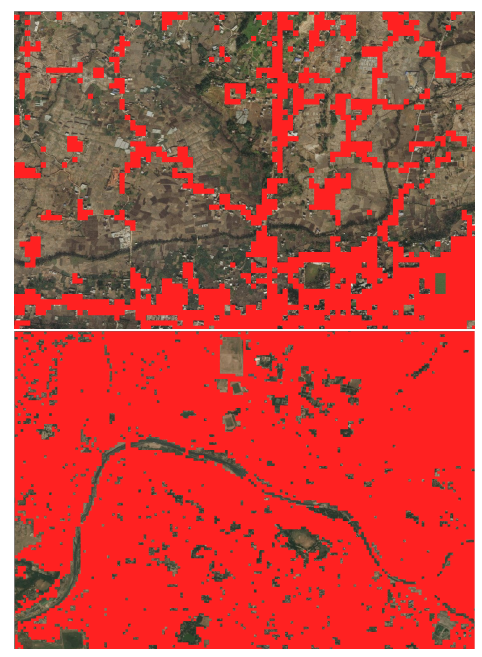

(b)

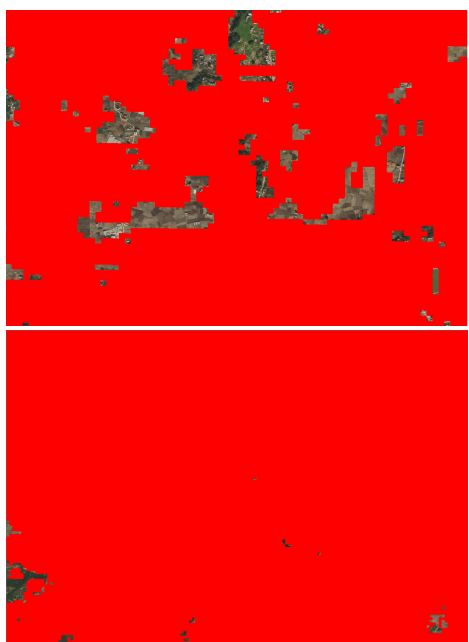

(c)

Figure 9. Comparison between the results and preexisting land cover: (a) latest high-resolution satellite images from Google, (b) the built-up area classification from the results of 2010, and (c) the built-up area from preexisting land covers of 2010.

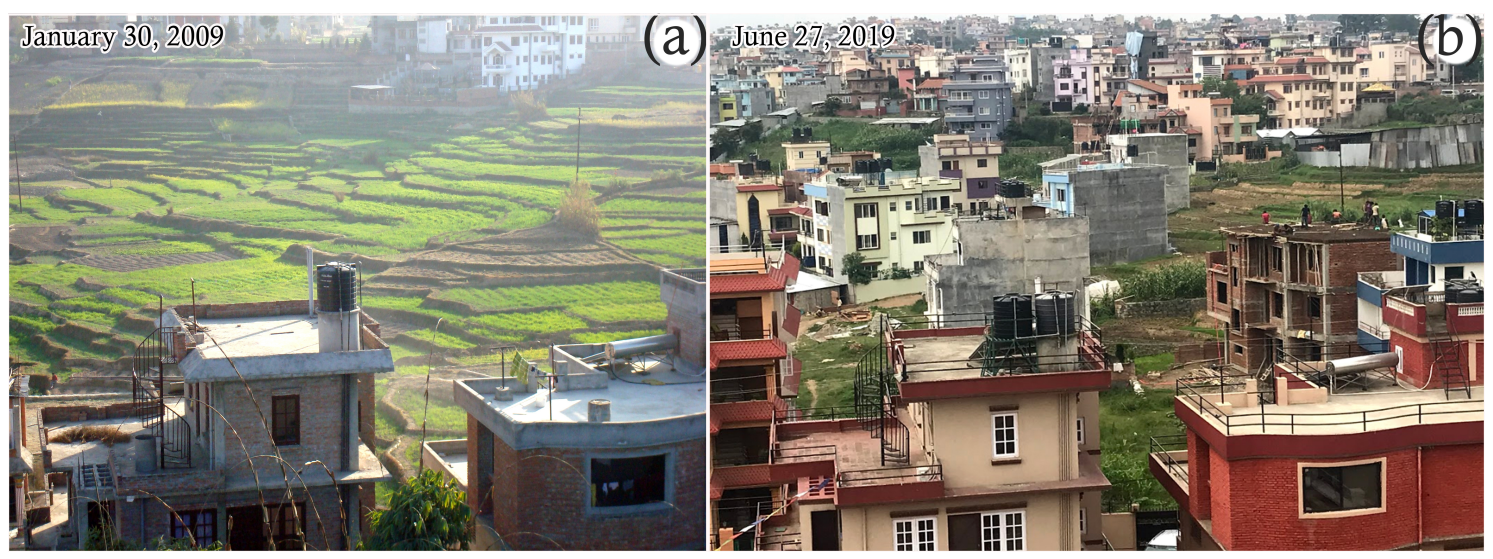

Figure 10. A repeat photo showing rapid expansion of the built-up areas of Khumaltar and Lalitpur (Lat: $27^{\circ} 38^{\prime} 48.83^{\prime \prime}$, Lon: $85^{\circ} 19^{\prime} 21.92^{\prime \prime}$ ) between 2009 (a) and 2019 (b).

\section{Discussion}

Kathmandu Valley has always exhibited a trend of urbanization. This was prevalent even before our chosen study period [49] and studies consistently predict the trend to continue [50]. Our study confirms these findings, as our results also show significant increases in urban area in the past 18 years. Unfortunately, the process of urbanization has also resulted in increased landscape fragmentation and heterogeneous land use $[47,67]$ which can be largely attributed to local government regulations [68] as well as the local land tenure system, which facilitated uncontrolled subdivisions on larger private plots [50], which has now been addressed by the government. Urbanization with these practices have been deemed economically inefficient among other things by Cadwallader [69]. Therefore, it is essential to have a layout plan for the city for better living places. To maximise effectiveness, town planning initiation should be targeted at the most expandable areas, where the impact is likely to be highest in coming years. However, to do this, it is first necessary to understand spatial expansion patterns at the municipality level. As capital cities are the engines of country growth and attention, developed built-up area maps can comprehensively provide support on spatial urban characteristic inheritance and spatial city planning system to release essential funds required for infrastructure development [70].

Traditional field-based modern equipment such as total stations are important for town planning application and can provide useful information at the centimetre accuracy. However, in most cases, 
field study data are not available regularly and are resource intensive to collect [47,50]. Considering the social and town planning value of urban footprints as well as the economic restrictions in developing it, our study has proposed a remote-sensing approach that leverages cloud computing technology and crowd-sourced data sets to develop a spatiotemporal assessment of urban sprawl in Kathmandu Valley. This approach allows planners to understand urban layouts and growth at a fraction of the computing power and cost than previous approaches.

The crowd-sourced data set of OSM are essentially manual digitizations over satellite images which are generally done by volunteers with local knowledge. This helps us correctly identify locations where manmade structures and features are present. Studies also explored past ground conditions from the historical repeat photos to see urban landscape change. Repeat geo-tagged picture is one of the most potent tools which efficiently can visualise and document long-term landscape conditions and its changes $[63,71]$. However, historical photos alone cannot identify urban areas in future years. By using photos in combination with the time series of yearly composite NDVIs, we have been able to accurately identify changes in built-up lands. Furthermore, our experiment with logical transitions in each pixel ensures that the classification was not only dependent on indices but was also based on on data that has higher confidence. From the results, it can be seen that this approach works well, especially in areas like Kathmandu valley where most of the land that is transitioning to settlements exhibits some form of vegetation prior to the transition. During built-up area mapping, one of the major concerns to upsurge is to distinguish barren, non-vegetated waterbodies and river bed areas from the built-up areas, as Landsat spectral information are the same in the non-vegetated areas [72]. We overcame that issue by fusing Landsat images and OSM layers together to develop the NDDBI.

Most previous studies have used OSM data directly in land-cover map generation [73-75] or have used them for generating training/validation points [29,76-78]. The lack of feature history in OSM data [36] limits its usage for time-series analyses, most of these previous studies have been limited to a single year. Similarly, using only NDVI and/or its derivatives would make it difficult to delineate classes such as urban, bare soil, and barren lands because of overlap in spectral reluctance $[24,79,80]$ even though remote-sensing data now have good temporal footprints. An alternate way of achieving high accuracy for urban mapping is potentially the use of very high-resolution satellite images. However, because of affordability and data-handling capacity issues for such images, those types of studies might be limited to a single-year and would not be able to determine urban growth over time. Therefore, by combine OSM and earth observation data, we were able to take advantage of the large volume of OSM data as well as the temporal resolution of freely available satellite images. This is the first time that OSM data has been combined with remote-sensing data directly to assess built-up area expansion spatially and temporally. Furthermore, this study takes advantage of the cloud computing capabilities of GEE, which means that the computing resource requirements on the producer's side are removed. This study provides us with a useful means of identifying priority areas to consider for interventions so that the haphazard development trend can be reduced and proper utility services are ensured.

The results show that the methodology has successfully detected the state of the built-up area in each year with an overall classification accuracy of $94.33 \%$. Results show that the urban area not only is increasing at an alarming rate, but also has been the highest in the last 18 years. This can be attributed to new settlements in the outer areas of the existing settlements rather than in empty pockets in the cores of existing settlements. Although expansion is more desirable than increasing the population density per unit area from a governance and human safety perspective, the results of decreasing natural land and the ecosystem services they provide could have equally detrimental economic and human health impacts. When our maps were compared with existing land-cover maps there was low agreement between the two set of maps; this was due to the fact that the previous land-cover map was heavily overestimating the built-up area, especially in the farmlands of Bhaktapur. It should be noted that the results of this study did not identify some isolated built-up areas due to missing data in the OSM data set. This could be ameliorated by land-based mapping in the regions where such settlements were missed. 
Despite the strengths, there are a few limitations to this approach as well. For this study, one of the most valuable resources used is OSM data, which is regularly updated by dedicated volunteered geographic information (VGI) efforts. As OSM data additions and manipulation are ongoing, the completeness and currency of data will always be in question. Törnros et al. [81] found in their study that a majority of areas in the study region, Ludwigshafen municipality, southwestern Germany, had less than $80 \%$ completeness. OSM data might be incomplete for a region of interest, so some urban areas might not be identified if there are missing data that are far from the mapped settlements. While using OSM data as a distance layer and combining it with the NDVI layer rather than using OSM as a direct source, like in this study, helps mitigate this issue, unmapped isolated settlements might be missed because of its significant distance from existing layers. Therefore, in order to achieve better results, currency and completeness of OSM data needs to be improved. Another limitation arises due to the fact that the study depends on the value of the 80th percentile of NDVI to detect changes in the temporal domain. This can cause false changes in the built-up areas in cases where, somehow, a particular area's NDVI value shows sudden increases or decreases [82]. It can also cause barren areas very close to the settlements to be flagged as built-up. Because of this, it was also identified that this method with NDVI would not be suitable for detecting urban areas and urban sprawl in regions predominantly covered in barren land or deserts.

Another thing to consider is that, because of the implementation of the logical change test, pixels that are misclassified in the later years result in misclassified pixels in prior years even if they were correctly detected in those previous years. Even though this one was not found to have been a significant issue in our study, it emphasizes the importance of proper selection of the threshold. However, there are some approaches that can be explored to take this method forward. In areas where OSM data is not complete other tertiary sources of buildings/roads data, for example data from local government, can be utilized. The method can also work with Object Based Image Analysis (OBIA) which is expected to give even better results as it works with homogeneous segments rather than individual pixels [83].

\section{Conclusions}

Mapping built-up areas using only earth observation data such as Landsat has, more often than not, led to inaccuracies in results due to the similar spectral nature between such areas and other areas like river beds and bare soils. With the use of vector data sets like OSM, we can obtain a highly accurate map. However, OSM data sets often lack timed information like when the feature was created, which makes studying the change in land difficult. The results show that we can successfully create accurate time-series maps of built-up areas by fusing the two data sets which takes advantage of their benefits while negating the limitations. In this study, built-up areas within Kathmandu Valley from 2000 to 2018 were mapped by using NDDBI, conceived for this study. The index was generated based on the integration of OSM layers and NDVI from Landsat images. This method signifies an operational cloud-based automated method of rapidly mapping built-up areas on an annual basis. From the results, it was observed that the rate of increase in built-up area is the highest over the last decade. This was mainly attributed to the spread of settlement over the densification of existing settlements. The results were concluded to be consistent and to represent the ground truth to a great degree based on high accuracy of overall classification, visual assessment of the result, and repeat photography. In comparison with existing land-cover maps, the result was found to be improved, especially in areas with higher spectral mixing. This methodology can be replicated for urban areas with similar settings where land conversion to built-up areas occur mostly at the expense of vegetated lands. The free and/or open nature of technologies also mean that it is an extremely low cost and feasible way to obtain the yearly information needed for improved urban land management, for support for conservation, or for other planning activities. A few things to consider to improve the performance of the results would be the completeness and currency of OSM data in the study region. 
Author Contributions: Conceptualization, methodology, validation, and formal analysis, N.K. and K.U.; writing-original draft preparation and writing—review and editing, N.K., K.U., M.A.M., and K.T.; Finally, all the authors read, edited, and critiqued the manuscript and approved the final version.

Funding: No direct external funding was received for this research.

Acknowledgments: We express our gratitude to David Molden, Director General and Eklabya Sharma, Deputy Director General of ICIMOD for the overall guidance. This study was partially supported by core funds of ICIMOD contributed by the governments of Afghanistan, Australia, Austria, Bangladesh, Bhutan, China, India, Myanmar, Nepal, Norway, Pakistan, Switzerland, and the United Kingdom. This paper has been prepared under the SERVIR-Hindu Kush Himalaya (SERVIR-HKH) initiative funded by the NASA and USAID. Our special gratitude goes to Ghulam Rasul, Regional Programme Manager, MENRIS and Birendra Bajracharya, Chief of Party, SERVIR-HKH for their encouragement and very active support in bringing out this work. We also thank the SERVIR RLCMS team for their assistance. Finally, we would like to thank those who reviewed the articles incomprehensibly and provided valuable suggestions to improve the manuscript.

Conflicts of Interest: The authors declare no conflict of interest. The views and interpretations in this publication are those of the authors. They are not necessarily attributable to ICIMOD and do not imply the expression of any opinion by ICIMOD concerning the legal status of any country, territory, city, or area of its authority or concerning the delimitation of its frontiers or boundaries or the endorsement of any product.

\section{Appendix A}

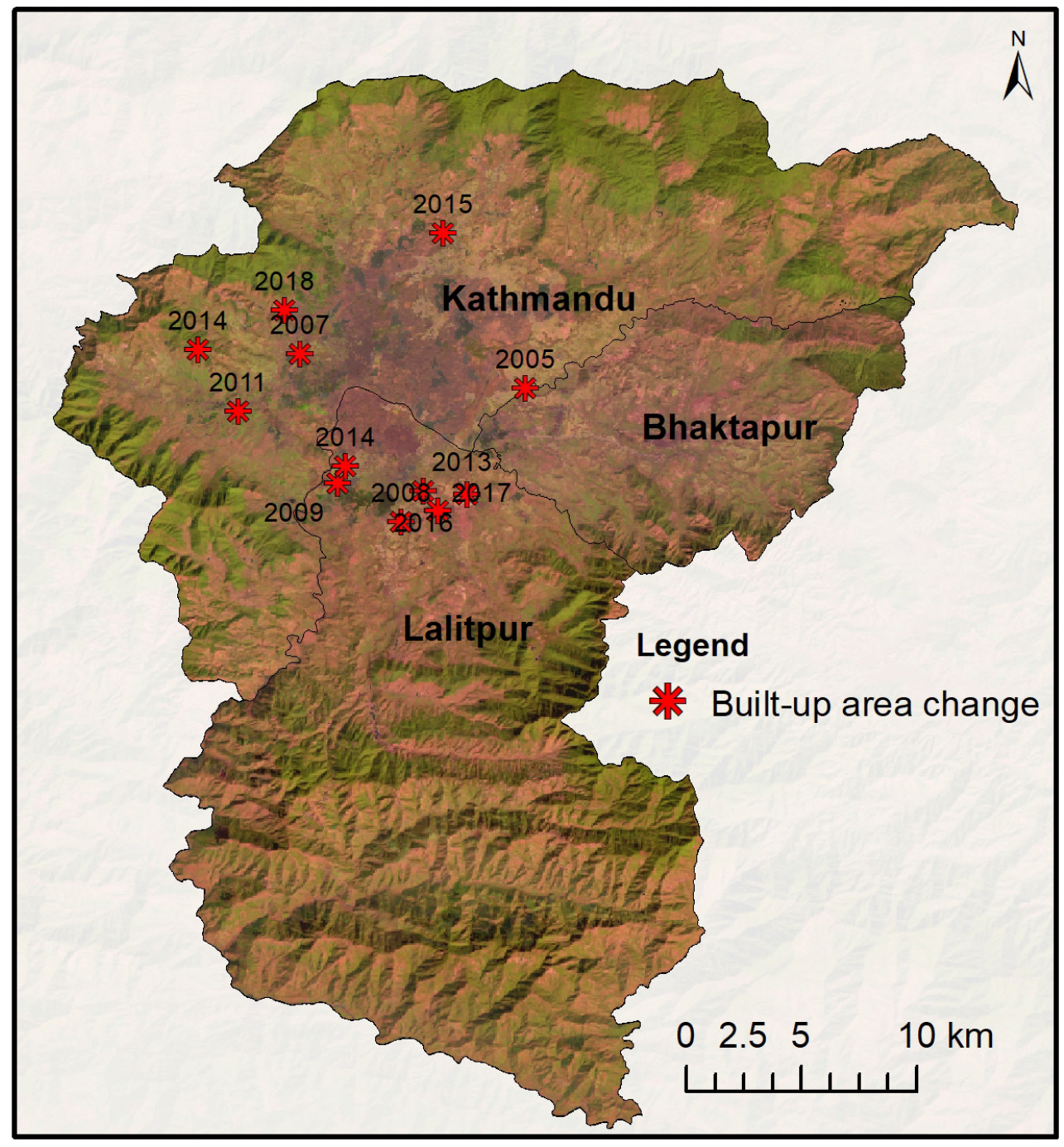

Figure A1. Spatial distribution of 12 points used to check the nature of change in NDVI resulting from land conversion to built-up areas. 


\section{Appendix B}

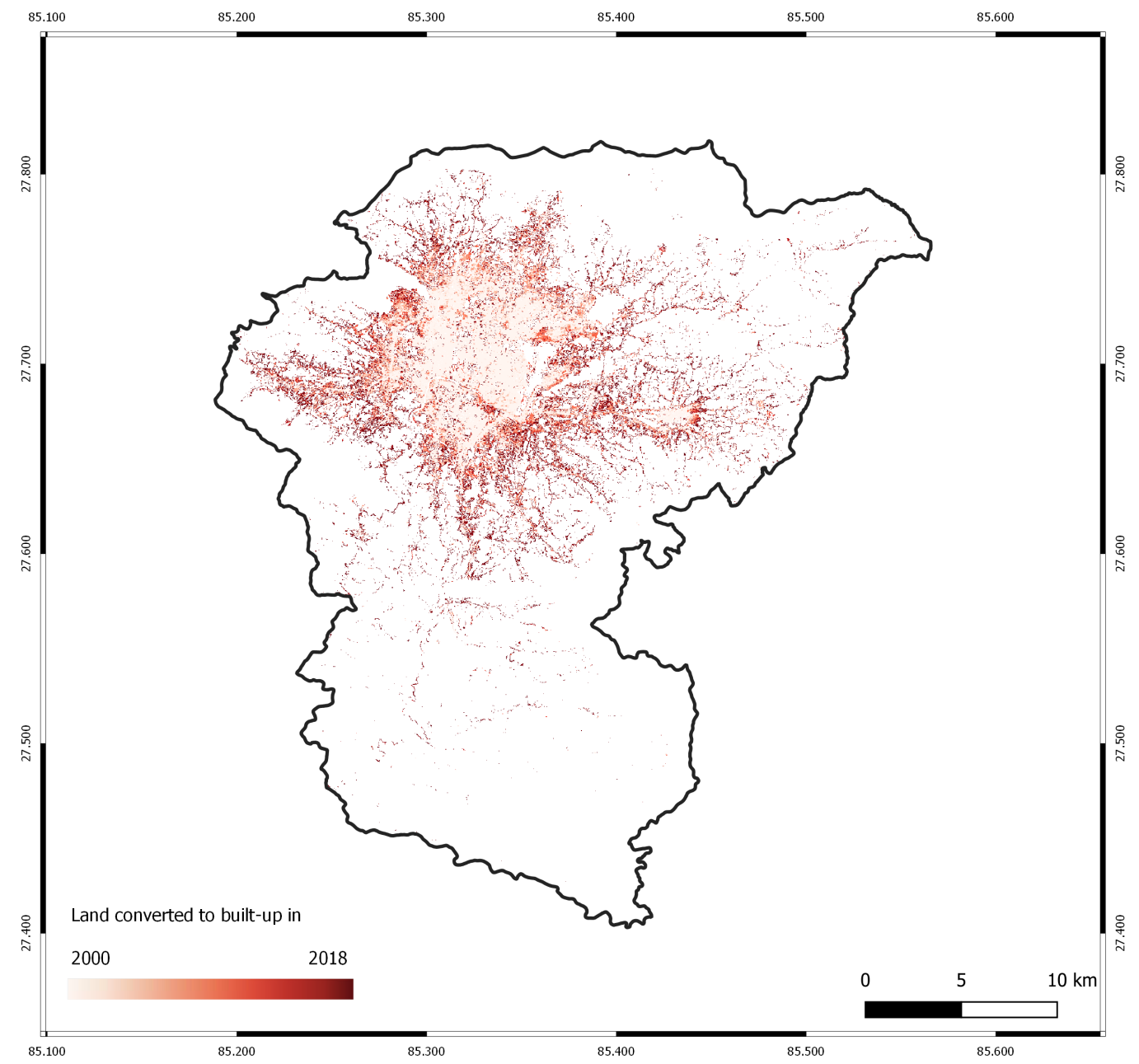

Figure A2. Map showing when land class changed to built-up areas in each area: The deeper red represents newer changes while the lighter color signifies older changes. White color represents areas that are not built-up.

\section{References}

1. Akbar, T.A.; Hassan, Q.K.; Ishaq, S.; Batool, M.; Butt, H.J.; Jabbar, H. Investigative spatial distribution and modelling of existing and future urban land changes and its impact on urbanization and economy. Remote Sens. 2019, 11, 105. [CrossRef]

2. UN Department of Economics and Social Affairs. World Urbanization Prospects: The 2018 Revision; United Nations Department of Economics and Social Affairs, Population Division: New York, NY, USA, 2018.

3. Seto, K.C.; Fragkias, M.; Güneralp, B.; Reilly, M.K. A meta-analysis of global urban land expansion. PLoS ONE 2011, 6, e23777. [CrossRef] [PubMed]

4. Angel, S.; Parent, J.; Civco, D.L.; Blei, A.M. Making Room for a Planet of Cities; Lincoln Institute of Land Policy: Cambridge, MA, USA, 2011.

5. Fragkias, M.; Güneralp, B.; Seto, K.C.; Goodness, J. A Synthesis of Global Urbanization Projections. In Urbanization, Biodiversity and Ecosystem Services: Challenges and Opportunities; Springer: Dordrecht, The Netherlands, 2013; pp. 409-435.

6. Xing, C.; Zhang, J. The preference for larger cities in China: Evidence from rural-urban migrants. In China Economic Review; Elsevier: Amsterdam, The Netherlands, 2017; Volume 40; pp. 72-90. 
7. Abhishek, N.; Jenamani, M.; Mahanty, B. Urban growth in Indian cities: Are the driving forces really changing? In Habitat International; Elsevier: Amsterdam, The Netherlands, 2017; Volume 69; pp. 48-57.

8. Zhang, Y.; Li, X.; Wen, J.; Liu, Q.; Yan, G. Improved topographic normalization for Landsat TM images by introducing the MODIS surface BRDF. Remote Sens. 2015, 7, 6558-6575. [CrossRef]

9. Silver, C Distressed city: The challenges of planning and managing megacity Jakarta. In Transforming Distressed Global Communities: Making Inclusive, Safe, Resilient, and Sustainable Cities; Routledge: London, UK, 2016; pp. 183-210

10. Landau, Loren B Displacement and the pursuit of urban protection: Forced migration, fluidity and global cities. In Forced Migration; Routledge: London, UK, 2018; pp. 106-125

11. Muggah, R.; Abdenur, A. Refugees and the City: The Twenty-First-Century Front Line; Centre for International Governance Innovation: Waterloo, ON, Canada, 2018

12. Abdullah, A.Y.M.; Masrur, A.; Adnan, M.S.G.; Baky, M.; Al, A.; Hassan, Q.K.; Dewan, A. Spatio-Temporal Patterns of Land Use/Land Cover Change in the Heterogeneous Coastal Region of Bangladesh between 1990 and 2017. Remote Sens. 2019, 11, 790. [CrossRef]

13. Elmqvist, T.; Redman, C.L.; Barthel, S.; Costanza, R. History of Urbanization and the Missing Ecology. In Urbanization, Biodiversity and Ecosystem Services: Challenges and Opportunities; Springer: Dordrecht, The Netherlands, 2013; pp. 13-30.

14. Shatkin, G. Futures of Crisis, Futures of Urban Political Theory: Flooding in Asian Coastal Megacities. International Journal of Urban and Regional Research; Wiley Online Library: Hoboken, NJ, USA, 2019; Volume 43; pp. 207-226;

15. Das, M.; Das, A. Dynamics of Urbanization and Its Impact on Urban Ecosystem Services (UESs): A Study of a Medium Size Town of West Bengal, Eastern India. Journal of Urban Management; Elsevier: Amsterdam, The Netherlands, 2019.

16. UN Department of Economics and Social Affairs. World Urbanization Prospects: The 2014 Revision; United Nations Department of Economics and Social Affairs, Population Division: New York, NY, USA, 2015.

17. Nepal, U. Population Situation Analysis of Nepal; Technical Report; UNFPA Nepal: Lalitpur, Nepal, 2017.

18. Pradhan, P.K. Population Growth, Migration and Urbanisation: Environmental Consequences in Kathmandu Valley, Nepal. In Environmental Change and Its Implications for Population Migration; Springer: Dordrecht, The Netherlands, 2004; pp. 177-199.

19. Khan, A.A. From the peaks and back: Mapping the emotions of trans-Himalayan children education migration journeys in Kathmandu, Nepal. Child. Geogr. 2018, 16, 616-627. [CrossRef]

20. Ishtiaque, A.; Shrestha, M.; Chhetri, N. Rapid urban growth in the Kathmandu Valley, Nepal: Monitoring land use land cover dynamics of a himalayan city with landsat imageries. Environments 2017, 4, 72. [CrossRef]

21. Maktav, D.; Erbek, F.; Jürgens, C. Remote sensing of urban areas. Int. J. Remote Sens. 2005, 26, 655-659. [CrossRef]

22. Patino, J.E.; Duque, J.C. A review of regional science applications of satellite remote sensing in urban settings. Comput. Environ. Urban Syst. 2013, 37, 1-17. [CrossRef]

23. He, C.; Shi, P.; Xie, D.; Zhao, Y. Improving the normalized difference built-up index to map urban built-up areas using a semiautomatic segmentation approach. Remote Sens. Lett. 2010, 1, 213-221. [CrossRef]

24. Rasul, A.; Balzter, H.; Ibrahim, G.; Hameed, H.; Wheeler, J.; Adamu, B.; Ibrahim, S.; Najmaddin, P. Applying Built-Up and Bare-Soil Indices from Landsat 8 to Cities in Dry Climates. Land 2018, 7, 81. [CrossRef]

25. Bouhennache, R.; Bouden, T.; Taleb-Ahmed, A.; Cheddad, A. A new spectral index for the extraction of built-up land features from Landsat 8 satellite imagery. Geocarto Int. 2018, 1-21. [CrossRef]

26. Bennett, J. OpenStreetMap; Packt Publishing Ltd.: Birmingham, UK, 2010.

27. Fonte, C.C.; Patriarca, J.A.; Minghini, M.; Antoniou, V.; See, L.; Brovelli, M.A. Using Openstreetmap to Create Land Use and Land Cover Maps: Development of an Application. In Geospatial Intelligence: Concepts, Methodologies, Tools, and Applications; IGI Global: Pennsylvania, PA, USA, 2019; pp. 1100-1123.

28. Haklay, M.; Weber, P. Openstreetmap: User-generated street maps. IEEE Pervasive Comput. 2008, 7, 12-18. [CrossRef]

29. Johnson, B.A.; Iizuka, K. Integrating OpenStreetMap crowdsourced data and Landsat time-series imagery for rapid land use/land cover (LULC) mapping: Case study of the Laguna de Bay area of the Philippines. Appl. Geogr. 2016, 67, 140-149. [CrossRef]

30. Forget, Y.; Linard, C.; Gilbert, M. Supervised Classification of Built-Up Areas in Sub-Saharan African Cities Using Landsat Imagery and OpenStreetMap. Remote Sens. 2018, 10, 1145. [CrossRef] 
31. Yang, D.; Fu, C.S.; Smith, A.C.; Yu, Q. Open land-use map: A regional land-use mapping strategy for incorporating OpenStreetMap with earth observations. Geospat. Inf. Sci. 2017, 20, 269-281. [CrossRef]

32. Kang, L.; Wang, Q.; Yan, H. Building extraction based on OpenStreetMap tags and very high spatial resolution image in urban area. Int. Arch. Photogramm. Remote Sens. Spat. Inf. Sci. 2018, 42, 3. [CrossRef]

33. Luo, N.; Wan, T.; Hao, H.; Lu, Q. Fusing High-Spatial-Resolution Remotely Sensed Imagery and OpenStreetMap Data for Land Cover Classification Over Urban Areas. Remote Sens. 2019, 11, 88. [CrossRef]

34. Fonte, C.; Minghini, M.; Patriarca, J.; Antoniou, V.; See, L.; Skopeliti, A. Generating up-to-date and detailed land use and land cover maps using OpenStreetMap and GlobeLand30. ISPRS Int. J. Geoinf. 2017, 6, 125. [CrossRef]

35. Estima, J.; Painho, M. Investigating the Potential of OpenStreetMap for Land Use/Land Cover Production: A Case Study for Continental Portugal. In OpenStreetMap in GIScience; Springer: Cham, Switzerland, 2015; pp. 273-293.

36. Viana, C.M.; Encalada, L.; Rocha, J. The value of OpenStreetMap Historical Contributions as a Source of Sampling Data for Multi-temporal Land Use/Cover Maps. ISPRS Int. J. Geoinf. 2019, 8, 116. [CrossRef]

37. Sharma, K.; Saraf, A.K.; Das, J.; Baral, S.S.; Borgohain, S.; Singh, G. Mapping and Change Detection Study of Nepal-2015 Earthquake Induced Landslides. J. Indian Soc. Remote Sens. 2018, 46, 605-615. [CrossRef]

38. Angiuli, E.; Trianni, G. Urban mapping in Landsat images based on normalized difference spectral vector. IEEE Geosci. Remote. Sens. Lett. 2013, 11, 661-665. [CrossRef]

39. Poursanidis, D.; Chrysoulakis, N.; Mitraka, Z. Landsat 8 vs. Landsat 5: A comparison based on urban and peri-urban land cover mapping. Int. J. Appl. Earth Obs. Geoinf. 2015, 35, 259-269. [CrossRef]

40. Liu, X.; Hu, G.; Chen, Y.; Li, X.; Xu, X.; Li, S.; Pei, F.; Wang, S. High-resolution multi-temporal mapping of global urban land using Landsat images based on the Google Earth Engine Platform. Remote Sens. Environ. 2018, 209, 227-239. [CrossRef]

41. Sidhu, N.; Pebesma, E.; Câmara, G. Using Google Earth Engine to detect land cover change: Singapore as a use case. Eur. J. Remote Sens. 2018, 51, 486-500. [CrossRef]

42. Gorelick, N.; Hancher, M.; Dixon, M.; Ilyushchenko, S.; Thau, D.; Moore, R. Google Earth Engine: Planetary-scale geospatial analysis for everyone. Remote Sens. Environ. 2017, 202, 18-27. [CrossRef]

43. Farr, T.G.; Rosen, P.A.; Caro, E.; Crippen, R.; Duren, R.; Hensley, S.; Kobrick, M.; Paller, M.; Rodriguez, E.; Roth, L.; et al. The shuttle radar topography mission. Rev. Geophys. 2007, 45. [CrossRef]

44. CBS. National Population and Housing Census 2011; National Report; Central Bureau of Statistics: Kathmandu, Nepal, 2012.

45. Gentle, P.; Thwaites, R.; Race, D.; Alexander, K.; Maraseni, T. Household and community responses to impacts of climate change in the rural hills of Nepal. Clim. Chang. 2018, 147, 267-282. [CrossRef]

46. Haack, B. A history and analysis of mapping urban expansion in the Kathmandu valley, Nepal. Cartogr. J. 2009, 46, 233-241. [CrossRef]

47. Thapa, R.; Murayama, Y. Examining spatiotemporal urbanization patterns in Kathmandu Valley, Nepal: Remote sensing and spatial metrics approaches. Remote Sens. 2009, 1, 534-556. [CrossRef]

48. Rimal, B. Application of remote sensing and GIS, land use/land cover change in Kathmandu metropolitan city, Nepal. J. Theor. Appl. Inf. Technol. 2011, 23, 80-86.

49. Haack, B.N.; Rafter, A. Urban growth analysis and modeling in the Kathmandu Valley, Nepal. Habitat Int. 2006, 30, 1056-1065. [CrossRef]

50. Thapa, R.B.; Murayama, Y. Urban growth modeling of Kathmandu metropolitan region, Nepal. Comput. Environ. Urban Syst. 2011, 35, 25-34. [CrossRef]

51. Wulder, M.A.; White, J.C.; Masek, J.G.; Dwyer, J.; Roy, D.P. Continuity of Landsat observations: Short term considerations. Remote Sens. Environ. 2011, 115, 747-751. [CrossRef]

52. Vermote, E.; Justice, C.; Claverie, M.; Franch, B. Preliminary analysis of the performance of the Landsat 8/OLI land surface reflectance product. Remote Sens. Environ. 2016, 185, 46-56. [CrossRef]

53. Holden, C.E.; Woodcock, C.E. An analysis of Landsat 7 and Landsat 8 underflight data and the implications for time series investigations. Remote Sens. Environ. 2016, 185, 16-36. [CrossRef]

54. Roy D.P.; Zhang, H.K.; Ju, J.; Gomez-Dans, J.L.; Lewis, P.E.; Schaaf, C.S.; Sun, Q.; Li, J.; Huang, H.; Kovalskyy, V. A general method to normalize Landsat reflectance data to nadir BRDF adjusted reflectance. Remote Sens. Environ. 2016, 176, 255-271. [CrossRef] 
55. Zhu, Z.; Woodcock, C.E. Object-based cloud and cloud shadow detection in Landsat imagery. Remote Sens. Environ. 2012, 118, 83-94. [CrossRef]

56. Chastain, R.; Housman, I.; Goldstein, J.; Finco, M. Empirical cross sensor comparison of Sentinel-2A and 2B MSI, Landsat-8 OLI, and Landsat-7 ETM+ top of atmosphere spectral characteristics over the conterminous United States. Remote Sens. Environ. 2019, 221, 274-285. [CrossRef]

57. Housman, I.; Stam, C.; Hancher, M. A quantitative evaluation of cloud and cloud shadow masking algorithms available in Google Earth Engine. Unpublished.

58. Poortinga, A.; Tenneson, K.; Shapiro, A.; Nquyen, Q.; San Aung, K.; Chishtie, F.; Saah, D. Mapping Plantations in Myanmar by Fusing Landsat-8, Sentinel-2 and Sentinel-1 Data along with Systematic Error Quantification. Remote Sens. 2019, 11, 831. [CrossRef]

59. Chettri, N.; Uddin, K.; Chaudhary, S.; Sharma, E. Linking spatio-temporal land cover change to biodiversity conservation in the Koshi Tappu Wildlife Reserve, Nepal. Diversity 2013, 5, 335-351. [CrossRef]

60. Eilers, P.H. A perfect smoother. Anal. Chem. 2003, 75, 3631-3636. [CrossRef] [PubMed]

61. Olofsson, P.; Foody, G.M.; Herold, M.; Stehman, S.V.; Woodcock, C.E.; Wulder, M.A. Good practices for estimating area and assessing accuracy of land change. Remote Sens. Environ. 2014, 148, 42-57. [CrossRef]

62. Niraula, R.R.; Gilani, H.; Pokharel, B.K.; Qamer, F.M. Measuring impacts of community forestry program through repeat photography and satellite remote sensing in the Dolakha district of Nepal. J. Environ. Manag. 2013, 126, 20-29. [CrossRef] [PubMed]

63. Bayr, U.; Puschmann, O. Automatic detection of woody vegetation in repeat landscape photographs using a convolutional neural network. Ecol. Informatics 2019, 50, 220-233. [CrossRef]

64. Fortin, J.A.; Fisher, J.T.; Rhemtulla, J.M.; Higgs, E.S. Estimates of landscape composition from terrestrial oblique photographs suggest homogenization of Rocky Mountain landscapes over the last century. Remote Sens. Ecol. Conserv. 2019, 5, 224-236. [CrossRef]

65. Nepal-National Population Census 2001, Tenth Census; Central Bureau of Statistics, National Planning Commission Secretariat, Government of Nepal: Kathmandu, Nepal, 2002.

66. Uddin, K.; Shrestha, H.L.; Murthy, M.; Bajracharya, B.; Shrestha, B.; Gilani, H.; Pradhan, S.; Dangol, B. Development of 2010 national land cover database for the Nepal. J. Environ. Manag. 2015, 148, 82-90. [CrossRef]

67. Bhattarai, K.; Conway, D. Urban vulnerabilities in the Kathmandu Valley, Nepal: Visualizations of human/hazard interactions. J. Geogr. Inf. Syst. 2010, 2, 63. [CrossRef]

68. Thapa, R.B.; Murayama, Y.; Ale, S. Kathmandu. Cities 2008, 25, 45-57. [CrossRef]

69. Cadwallader, M.T. Urban Geography: An Analytical Approach; Prentice Hall: Upper Saddle River, NJ, USA, 1996.

70. Rahman, M.S.; Mohiuddin, H.; Kafy, A.A.; Sheel, P.K.; Di, L. Classification of cities in Bangladesh based on remote sensing derived spatial characteristics. J. Urban Manag. 2019, 8, 206-224. [CrossRef]

71. Byers, A. An assessment of landscape change in the Khumbu region of Nepal using repeat photography. Mt. Res. Dev. 1987, 7,77-81. [CrossRef]

72. As-syakur, A.; Adnyana, I.; Arthana, I.W.; Nuarsa, I.W. Enhanced built-up and bareness index (EBBI) for mapping built-up and bare land in an urban area. Remote Sens. 2012, 4, 2957-2970. [CrossRef]

73. Jokar Arsanjani, J.; Helbich, M.; Bakillah, M.; Hagenauer, J.; Zipf, A. Toward mapping land-use patterns from volunteered geographic information. Int. J. Geogr. Inf. Sci. 2013, 27, 2264-2278. [CrossRef]

74. Mooney, P.; Corcoran, P.; Winstanley, A. A study of data representation of natural features in openstreetmap. Proc. GISci. 2010, 150, 150-156.

75. Schultz, M.; Voss, J.; Auer, M.; Carter, S.; Zipf, A. Open land cover from OpenStreetMap and remote sensing. Int. J. Appl. Earth Obs. Geoinf. 2017, 63, 206-213. [CrossRef]

76. Arsanjani, J.J.; Helbich, M.; Bakillah, M. Exploiting volunteered geographic information to ease land use mapping of an urban landscape. In Proceedings of the International Archives of the Photogrammetry, Remote Sensing and Spatial Information Sciences, London, UK, 29-31 May 2013; pp. 51-55.

77. Estima, J.; Painho, M. Exploratory analysis of OpenStreetMap for land use classification. In Proceedings of the Second ACM SIGSPATIAL International Workshop on Crowdsourced and Volunteered Geographic Information, Orlando, FL, USA, 5 November 2013; ACM: New York, NY, USA, 2013; pp. 39-46.

78. Akay, S.; Sertel, E. Urban Land Cover/use Change Detection Using High Resolution SPOT 5 and SPOT 6 Images and Urban Atlas Nomenclature. Int. Arch. Photogramm. Remote Sens. Spat. Inf. Sci. 2016, 41, 789-796. [CrossRef] 
79. Zha, Y.; Gao, J.; Ni, S. Use of normalized difference built-up index in automatically mapping urban areas from TM imagery. Int. J. Remote Sens. 2003, 24, 583-594. [CrossRef]

80. Uddin, K.; Matin, M.A.; Meyer, F.J. Operational Flood Mapping Using Multi-Temporal Sentinel-1 SAR Images: A Case Study from Bangladesh. Remote Sens. 2019, 11, 1581. [CrossRef]

81. Törnros, T.; Dorn, H.; Hahmann, S.; Zipf, A. Uncertainties of completeness measures in OpenStreetMap-A case study for buildings in a medium-sized German city. ISPRS Ann. Photogramm. Remote Sens. Spat. Inf. Sci. 2015, 2, 353. [CrossRef]

82. Uddin, K.; Abdul Matin, M.; Maharjan, S. Assessment of land cover change and its impact on changes in soil erosion risk in Nepal. Sustainability 2018, 10, 4715. [CrossRef]

83. Bajracharya, B.; Uddin, K.; Chettri, N.; Shrestha, B.; Siddiqui, S. Understanding land cover change using a harmonized classification system in the Himalaya; Mountain Research and Development. BioOne 2010, 30, 143-157.

(C) 2019 by the authors. Licensee MDPI, Basel, Switzerland. This article is an open access article distributed under the terms and conditions of the Creative Commons Attribution (CC BY) license (http:// creativecommons.org/licenses/by/4.0/). 